\title{
REVIEW
}

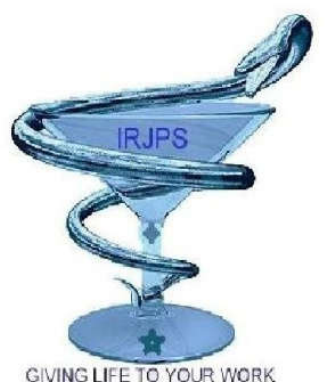

\section{COLORECTAL CANCER: A REVIEW OF DISEASE DIAGNOSIS, SURGICAL INTERVENTION AND TREATMENT PROCEDURES}

\author{
Ranjana Ramesh ${ }^{1}$, Dorin Dsouza ${ }^{2}$, Yogish. $S^{1}$, Mahadeva Murthy $S^{3 *}$ \\ ${ }^{1,}$ Skanda Life sciences Pvt. Ltd, Bangalore, \\ ${ }^{2}$ Department of Studies in Microbiology, University of Mysore, Mysore, \\ ${ }^{3}$ Department of Microbiology, Yuvaraja's College, University of Mysore, Mysuru-570 005, India
}

\section{Submitted on: 22.02.18; $\quad$ Revised on: 06.03.18; $\quad$ Accepted on: 14.03.18}

\begin{abstract}
:
Colorectal cancer, also known as bowel or colon cancer is associated with colon or rectum sections of the intestine. Globally, more than 1 million people are affected by colorectal cancer every year and have been the cause for death in about 715,000 in 2010. As of 2012, it is the second most common cause of cancer in women $(9.2 \%$ of diagnoses) and the third most common in men $(10.0 \%)$. It also accounts for the fourth most common cause of cancer death after lung, stomach, and liver cancer. Colorectal cancer develops mostly during aging and as a reason of increasing lifestyle disorders as well as rarely through genetic heredity. Hence, this grows immense interest in the diagnosis, cure, genetic counseling and general awareness about the disease. Surgery, chemotherapy and radiation therapy, either individually or carried out in conjecture, seems to be the best treatment for the disease. Assessment of risk factors is very important in the early detection of the disease. This review aims to compile broadly the available knowledge on the causes of colorectal cancer, the methods for prevention, therapy or treatment of the disease and the guidelines for genetic counseling and general awareness. It also helps in understanding the risk factors in the development of disease.
\end{abstract}

KEYWORDS: Colorectal cancer, Colonoscopy, MRI, CT scan, Colon cancer staging, Genetic counselling

Corresponding Author: Mahadeva Murthy S

E-mail: smmurthy2025@gmail.com Mobile no: +919845074086
Indian Research Journal of Pharmacy and Science; 16(2018)1260-1279;

Journal Home Page: https://www.irjps.in DOI: 10.21276/irjps.2018.5.1.5 


\section{INTRODUCTION:}

Colorectal cancer originates in inner epithelium lining of the colon or the rectum of the alimentary canal. These cancers are also referred individually as either colon cancer or rectal cancer, depending on the location of tumor origin and they have many features in common ${ }^{1}$. Most colorectal cancers have longer prognosis time and develop slowly over several years. Prior to the development of the cancer, a growth of tissue or usually a tumor gives rise to a non-cancerous polyp on the inner lining of the colon or rectum. A benign polyp may remain benign or non-cancerous and not always convert to cancerous tumor. The probabilities of benign tumors to get converted into malignant forms depend upon the type of polyp. Adenomatous polyps (adenomas) are a type of polyps that are precancerous and can change into cancer. Hyperplastic polyps and inflammatory polyps are generally not pre-cancerous. However, it is believed amongst certain cancer medical specialist that certain hyperplastic polyps can become pre-cancerous or might even have a greater risk of developing adenomas and cancer, particularly when these polyps grow in the ascending colon.

Another type of pre-cancerous condition is called 'dysplasia'. Dysplasia occurs in the lining of the colon or rectum and microscopy reveals abnormality in these cells but without similarity to true cancer cells. These cells could potentially change into cancerous cells over time. Dysplasia is often observed in people having a long running medical history of diseases such as ulcerative colitis or Crohn's disease which cause chronic inflammation of the colon ${ }^{1,2}$.

If cancer develops within a polyp, it can eventually begin to grow into the walls of the colon or rectum. When cancer cells are located on the wall, they invade into blood vessels or lymph vessels. They first drain into nearby lymph nodes, which are beanshaped structures containing immune cells. Once cancer cells spread into blood or lymph vessels, they can travel to nearby lymph nodes or to distant parts of the body, such as the liver, a process called as metastasis ${ }^{2}$. There are several types of colon cancers based on the site of development (table 1).

Table 1: Types of Cancers in the Colon and Rectum

\begin{tabular}{llll}
\hline SI No. & Types & Site of development & Reference \\
\hline 1 & Adenocarcinomas & Cells of mucus gland & 3 \\
2 & Carcinoid tumors & Specialized hormone cells in intestine & 4 \\
3 & Gastrointestinal stromal & Interstitial cells of cajal & 5 \\
& tumors (GISTs) & Immune cells of lymphnodes & 6 \\
4 & Lymphomas & Blood vessels in the wall of colon and rectum & 7 \\
5 & Sarcomas & & \\
\hline
\end{tabular}

\section{Key statistics about colorectal cancer}

Colorectal cancer is the third most common cancer diagnosed in both men and women in the United States. The American Cancer Society estimated a total of 96,830 cases of colon cancer and 40,000 new cases of rectal cancer in the United States alone for the year 2014. Overall, the lifetime risk of developing colorectal cancer is about 1 in $20(5 \%)$. This risk is slightly lower in women than in men ${ }^{1}$.

The death rate (the number of deaths per 100,000 people per year) from colorectal cancer has been dropping in both men and women in the last 20 years.

There are few likely reasons for this, one of which is that the polyps are rapidly screened and removed before they develop into cancers. Screening has allowed detection of colorectal cancers early when the disease is still easily curable. In addition to this, the treatment for colorectal cancer has improved over the last several years. As a result, there are now more than 1 million survivors of colorectal cancer in the United States ${ }^{1}$.

\section{People at increased or high risk}

The following conditions are laid by the American society for colon cancer for suspects placed at higher than average risk:

- A personal history of colorectal cancer or adenomatous polyps. 
- A personal history of inflammatory bowel disease (ulcerative colitis or Crohn's disease).

- A strong family history of colorectal cancer or polyps.

- A known family history of a hereditary colorectal cancer syndrome such as familial adenomatous polyposis (FAP) or hereditary nonpolyposis colon cancer (HNPCC).

Table 2 lists the suggested screening guidelines for suspects with increased or high risk of colorectal cancer based on specific risk factors.

Table 2: American Cancer Society Guidelines on Screening and Surveillance for the early detection of colorectal adenomas and cancer in people at high risk

(HIGH RISK - Patients with a history of polyps on prior colonoscopy)

\begin{tabular}{|c|c|c|c|}
\hline Risk Category & Age to Begin & Recommended Test(s) & Comment \\
\hline $\begin{array}{l}\text { People with small } \\
\text { rectal hyperplastic } \\
\text { polyps. }\end{array}$ & $\begin{array}{l}\text { Same as those at } \\
\text { average risk. }\end{array}$ & $\begin{array}{l}\text { Colonoscopy, or } \\
\text { other screening } \\
\text { options at same } \\
\text { intervals as for } \\
\text { those at average } \\
\text { risk. }\end{array}$ & $\begin{array}{l}\text { Those with hyperplastic } \\
\text { polyposis syndrome are at an } \\
\text { increased risk for adenomatous } \\
\text { polyps and } \\
\text { cancer and should have } \\
\text { more intensive follow-up. }\end{array}$ \\
\hline $\begin{array}{l}\text { People with } 1 \text { or } 2 \\
\text { small } \\
\text { tubular adenomas less than } \\
1 \mathrm{~cm} \text {, with } \\
\text { low-grade dysplasia. }\end{array}$ & $\begin{array}{l}5 \text { to } 10 \text { years after } \\
\text { the polyps are } \\
\text { removed. }\end{array}$ & Colonoscopy. & $\begin{array}{l}\text { Time between tests } \\
\text { should be based on other } \\
\text { factors such as prior } \\
\text { colonoscopy findings, } \\
\text { family history, and } \\
\text { patient and doctor } \\
\text { preferences }\end{array}$ \\
\hline $\begin{array}{l}\text { People with } 3 \text { to } 10 \\
\text { adenomas, or a large }(>1 \\
\mathrm{cm}) \text { adenoma, or any } \\
\text { adenomas with high grade } \\
\text { dysplasia or villous } \\
\text { features. }\end{array}$ & $\begin{array}{l}3 \text { years after the } \\
\text { polyps are removed. }\end{array}$ & Colonoscopy. & $\begin{array}{l}\text { Adenomas must have } \\
\text { been completely } \\
\text { removed. If colonoscopy } \\
\text { is normal or shows only } 1 \\
\text { or } 2 \text { small tubular adenomas } \\
\text { with low-grade } \\
\text { dysplasia, future } \\
\text { colonoscopies can be } \\
\text { done every } 5 \text { years. }\end{array}$ \\
\hline $\begin{array}{l}\text { People with more than } \\
10 \text { adenomas on a } \\
\text { single exam. }\end{array}$ & $\begin{array}{l}\text { Within } 3 \text { years after the } \\
\text { polyps are removed. }\end{array}$ & Colonoscopy. & $\begin{array}{l}\text { Doctor should consider } \\
\text { the possibility of genetic } \\
\text { syndrome (such as FAP } \\
\text { or HNPCC). }\end{array}$ \\
\hline $\begin{array}{l}\text { People with sessile } \\
\text { adenomas that are } \\
\text { removed in pieces. }\end{array}$ & $\begin{array}{l}2 \text { to } 6 \text { months after } \\
\text { adenoma removal. }\end{array}$ & Colonoscopy. & $\begin{array}{l}\text { If entire adenoma has } \\
\text { been removed, further } \\
\text { testing should be based } \\
\text { on doctor's judgment. }\end{array}$ \\
\hline
\end{tabular}

\section{Risk factors associated with colorectal cancer}

Owning a risk factor, or even several risk factors, does not necessarily imply that the cancerous disease would be acquired. Furthermore, sometimes patients having no known risk factors could also acquire the disease. Additionally, in patients suffering colorectal cancer and possessing a risk factor, it is often very hard to know how much that risk factor may have contributed to the development of cancer. Following are some of the risk factors that 
may increase a person's chance of developing colorectal polyps or colorectal cancer.

\section{Unavoidable risk factors}

Age: Younger adults can develop colorectal cancer at high frequency, but the chances increase markedly after the age of 50 years. About 9 out of 10 people diagnosed with colorectal cancer are of aged 50 years ${ }^{8}$.

Personal history of colorectal polyps or colorectal cancer: A prior history of adenomatous polyps (adenomas) provides an increased risk of developing colorectal cancer. This is especially true if the polyps are large sized or if they are numerous in numbers. Survivors of colorectal cancer, even though the cancer is completely removed, are more likely to develop new cancers in other areas of the colon and rectum. The chances of such an occurrence are greater if the first colorectal cancer was acquired at a young age.

Personal history of inflammatory bowel disease: Patients of Inflammatory Bowel Disease (IBD) for many years often develop dysplasia ${ }^{9}$. IBD, which includes ulcerative colitis and Crohn's disease, is a condition in which the colon is inflamed over a long period of time. IBD increases the risk of developing colorectal cancer, and the patient may need to start being screened for colorectal cancer at an earlier age and be screened on a more frequent basis.

Family history of colorectal cancer or adenomatous polyps: People having a family history of colorectal cancer in one or more first-degree relatives (parents, siblings, or children) are at increased risk of the disease ${ }^{10}$. The risk is higher if the relative was diagnosed with cancer at a younger age of 45 years. Cancers can 'run in the family' due to inherited genes or shared environmental factors, or combination of these.

Inherited syndromes: About 5-10\% of people who develop colorectal cancer have inherited gene defects (mutations) ${ }^{11}$. Identifying families with these inherited syndromes is important to implement proper measures for curing. Genetic counseling often helps in reviewing the family medical tree to estimate the likelihood of being affected by the disease in families with inherited cancer syndrome. The two most common inherited syndromes linked with colorectal cancers are familial adenomatous polyposis (FAP) and hereditary non-polyposis colorectal cancer (HNPCC).

Familial adenomatous polyposis (FAP): FAP is caused by mutations in the heritable $A P C$ gene ${ }^{12}$. About $1 \%$ of all colorectal cancers are due to abnormal FAP. Patients with FAP typically develop hundreds to thousands of polyps in their colon and rectum, usually in their teens or early adulthood.

Hereditary non-polyposis colon cancer (HNPCC): HNPCC, also known as Lynch syndrome, accounts for about $2 \%$ to $3 \%$ of all colorectal cancers

13. This disorder is caused by an inherited defect in either the gene $M L H 1$ or $M S H 2$, but other genes are also known to be associated with HNPCC. These genes are involved in repair against DNA damage. The cancers in this syndrome also develop at relatively young age, although not as young as in FAP. The lifetime risk of colorectal cancer in people with this condition may be as high as $80 \%$. Other cancers linked with HNPCC include cancer of the ovary, stomach, small bowel, pancreas, kidney, brain, ureters (tubes that carry urine from the kidneys to the bladder), and bile duct.

Turcot syndrome: This is a rare inherited condition in which people are at increased risk of adenomatous polyps and colorectal cancer, as well as brain tumors. There are two types of Turcot syndrome; (i) Caused by gene changes like those seen in FAP, in which cases the brain tumors are medulloblastomas; and, (ii) Caused by gene changes like those seen in HNPCC, in which cases the brain tumors are glioblastomas ${ }^{14}$.

Peutz-Jeghers syndrome: People with this rare inherited condition tend to have freckles around the mouth or sometimes on the hands and feet and a special type of polyp in their digestive tracts called hamartomas ${ }^{15}$. They are at high risk for colorectal cancer, as well as several other cancers, which usually appear at a younger than normal age. This syndrome is caused by mutations in the gene STK1.

MUTYH-associated polyposis: Patients with this syndrome develop colon polyps that become cancerous if the colon is not removed ${ }^{16}$. This syndrome is caused by mutations in the gene MUTYH.

Racial and ethnic background: African Americans have the highest colorectal cancer incidence and mortality rates of all racial groups in the United States. Jews of Eastern European descent 
(Ashkenazi Jews) have one of the highest colorectal cancer risks of any ethnic group in the world. Several gene mutations leading to an increased risk of colorectal cancer have been found in this group. The most common of these DNA changes, called the I1307K APC mutation, is present in about $6 \%$ of American Jews ${ }^{17}$.

Type 2 diabetes: People with type 2 (noninsulin dependent) diabetes have an increased risk of developing colorectal cancer ${ }^{18}$.

\section{Avoidable risk factors}

Lifestyle-related factors: Factors such as diet, weight, and exercise are linked with risk for development of colorectal cancer ${ }^{19}$. Red meats (such as beef, lamb, or liver) and processed meats (hot dogs and some luncheon meats) has high risk of colorectal cancer. In contrary, diets rich in vegetables, fruits, and whole grains have been linked with a decreased risk of colorectal cancer. Obesity raises the risk of colon cancer in both men and women, but the link seems to be stronger in men. In addition, increasing the physical activity may help in reducing the risk of developing cancer. Further long term smokers and alcohol users are more prone to colorectal cancers ${ }^{7,8}$.

\section{Factors having uncertain, controversial or unproven effects on colorectal cancer: Disturbed day-night circadian rhythm:} Results of earlier study suggested that disturbed daynight rhythm by working a night shift at least 3 nights a month for at least 15 years may increase the risk of colorectal cancer. The study suggested that this might be due to changes in levels of melatonin (a hormone that responds to changes in light) in the body ${ }^{20}$.

Previous treatment: Some studies indicate that men who survive testicular cancer seem to have a higher rate of colorectal cancer ${ }^{21}$. In addition, radiation therapy to treat prostate cancer might increase the risk of rectal cancer ${ }^{22}$. The American Cancer Society and several other medical organizations recommend earlier screening for people with prostate cancer for risk of colorectal cancer.

\section{Major causes of colorectal cancer}

The exact cause of most colorectal cancers is unknown but an enormous research is being carried out in this area. Oncogenes and tumor suppressor genes are important in cancer development as well.
Cancers can be caused by DNA mutations that abnormally turn on oncogenes or turn off tumor suppressor genes. Gene mutations is one of reason for development of colorectal cancer. They can heritable or non-heritable.

Inherited gene mutations: A small portion of colorectal cancers are known to be caused by inherited gene mutations ${ }^{23}$. For example, inherited changes in a gene called $A P C$ are responsible for familial adenomatous polyposis (FAP) and Gardner syndrome. In people who have inherited changes in the $A P C$ gene, the brake in cell growth is turned off, causing hundreds of polyps to form in the colon. Hereditary non-polyposis colon cancer (HNPCC), also known as Lynch syndrome, is caused by changes in genes that normally help a cell to repair faulty DNA. For example genes like $M L H 1, M S H 2, M L H 3$, MSH6, PMS1, or $P M^{11}$. TGFBR2 is another gene linked to HNPCC ${ }^{24}$. It helps regulate cell growth. The rare Peutz-Jeghers syndrome is caused by inherited changes in the STK11 gene ${ }^{15}$.

Acquired gene mutations: In most cases, the DNA mutations that lead to cancer are acquired during a person's life rather than having been inherited. Mutations may occur in the genes such as $K R A S, T P 53$, and SMAD4 ${ }^{25}$ that can lead the cells to grow and spread uncontrollably.

\section{Colorectal cancer staging}

A staging system is a standardized way to assess the extent of the cancer ${ }^{2}$. The stage of the cancer describes the extent of the cancer in the body and is based on how far the cancer has grown into the wall of the intestine, whether or not it has reached nearby structures, and whether or not it has spread to the lymph nodes or distant organs. The stage of a cancer is one of the most important factors in determining prognosis and treatment options. It is based on the results of physical examinations, biopsies, and imaging tests (CT or MRI scan, $\mathrm{x}$-rays, PET scan, etc.), as well as the results of surgery. There are two types of staging for colorectal cancer ${ }^{26}$ : (i) The clinical stage, which is the best estimate of the extent of disease and is based on the results of the physical examination, biopsy, and imaging tests, and (ii) pathological stage, which is based on the same factors as the clinical stage and including the result of the surgery. Pathologic staging is likely to be more accurate than clinical staging, as it provides a 'first- 
hand impression' of the extent of the disease. The most commonly used staging system for colorectal cancer is that of the American Joint Committee on Cancer (AJCC), sometimes also known as the TNM system ${ }^{27}$. The TNM system describes 3 key pieces of information:

(i) $\mathbf{T}$ describes the extent to which the main or primary tumor has grown into the wall of the intestine and if it has grown into nearby areas.

(ii) $\quad \mathbf{N}$ describes the extent of spread to nearby lymph nodes.

(iii) $\mathbf{M}$ indicates if the cancer has metastasized to other organs of the body. Colorectal cancer can spread almost anywhere in the body, but the most common sites of spread are the liver and lungs.

Numbers or letters appear after $\mathrm{T}, \mathrm{N}$, and $\mathrm{M}$ to provide more details about each of these factors. The numbers 0 through 4 indicate increasing severity. The letter X means "cannot be assessed because the information is not available."

\section{Grade of colorectal cancer}

Another factor that can affect the outlook for survival is the grade of the cancer ${ }^{27}$. Grade is a description of how closely the cancer looks to a normal colorectal tissue when seen under a microscope. The scale used for grading colorectal cancers is counted from $\mathrm{G} 1$, where the cancer looks much like normal colorectal tissue to G4, where the cancer looks very abnormal. The grades G2 and G3 fall intermediate to these. Most of the time, the outlook is better for low-grade cancers than it is for high-grade cancers of the same stage. Grade is sometimes used to decide if an additional (adjuvant) treatment is required to accompany chemotherapy after surgery.

\section{Tests for detection of Colorectal cancer}

Different tests are used to screen for colorectal cancers and are classified into two broad groups (Table 3): (i) Tests that can detect both colorectal polyps and cancer-These tests involve visual imaging of the colon to identify abnormal areas. This is carried out by either using a scope inserted into the rectum or with special imaging ( $\mathrm{x}$ ray) tests. Polyps found before they become cancerous can be removed, so these tests may be classified under preventive measures and are most preferred methods. According to the recommendations of the American Society of colorectal cancer, both men and women beginning at age 50 years with an average risk for developing colorectal cancer (ii) Tests that mainly detect cancerThese involves testing of the stool (feces) for signs of cancers. These tests are less invasive and easier, but they are less likely to detect polyps.

Table 3: Tests to detect colorectal cancer

\begin{tabular}{|c|c|}
\hline Tests that detect polyps and cancer & Tests that mainly detect cancer \\
\hline Flexible sigmoidoscopy once in every 5 years* & $\begin{array}{l}\text { Fecal occult blood test (FOBT) once in every year*, or } \\
* *\end{array}$ \\
\hline Colonoscopy once in every 10 years & $\begin{array}{l}\text { Fecal immunochemical test (FIT) once in every year*, or } \\
* *\end{array}$ \\
\hline $\begin{array}{l}\text { Double-contrast barium enema once in every } 5 \text { years* } \\
\text { CT colonography (virtual colonoscopy) once in every } 5 \\
\text { years* }\end{array}$ & Stool DNA test (sDNA)*** \\
\hline
\end{tabular}

*Colonoscopy should be done if test results are positive.

**For FOBT or FIT used as a screening test, the take-home multiple sample method should be used. An FOBT or FIT done during a digital rectal exam in the doctor's office is not adequate for screening.

***This test is a part of the ACS guidelines published in 2008, but it is no longer available.

\section{Diagnosis methods available for detection of colorectal cancer}

Symptoms of colorectal cancer usually only appear only at advanced stages of the disease. Since colorectal cancer is often diagnosed only after the symptoms appear and most people with early stages of colorectal cancer do not exhibit symptoms of the disease, risk factors are often used as the basis for diagnosis. A diagnostic test based on the symptoms would involve the following procedures.

(a) Medical history and physical examination: A complete check for symptoms and risk factors, 
including, familial history, physical examination for presence of masses or enlarged organs in abdomen is performed wherein a digital rectal exam (DRE) is commonly carried out.

(b) Blood tests: Blood test helps in diagnosis of colorectal cancer or to monitor the disease if already diagnosed with cancer. Complete blood count (CBC) is used to determine the blood count and especially the Red blood corpuscles as many people suffering from colorectal cancer face anemia due to prolonged bleeding from the tumor. Studying liver enzymes in the serum is also recommended as the colorectal cancer easily spreads to liver. Colorectal cancer cells biosynthesize specific substances like carcinoembryonicantigen (CEA) and CA 19-9, that are released into the bloodstream and serve as markers for cancers ${ }^{28,29}$. Detection of tumor markers in blood stream help in monitoring the disease and in post-treatment prognosis for reappearance of the cancer.

\section{Biological tests to detect colorectal polyps or cancer}

Once preliminary diagnosis indicates abnormality with respect to possibilities of colorectal cancer, further tests to detect the cancer is recommended.

Biopsy: Usually if a diagnostic test results in suspicion indicating colorectal cancer, it is biopsied during a colonoscopy. Biopsy samples (from colonoscopy or surgery) are most commonly examined using microscope by the pathologist. Other lab tests can be done on biopsy specimens to help better classify the cancer including genetic changes. For example, test for $K R A S$ mutant gene. Sometimes, mutations in the $B R A F$ gene are also tested ${ }^{30}$. Tumor tissues can also be tested for DNA changes in microsatellites and it is called microsatellite instability (MSI) testing ${ }^{31}$. Microsatellite instability is present in most colorectal cancers caused by hereditary non-polyposis colon cancer (HNPCC). There are 2 reasons to test colorectal cancer for MSI. The first reason is to identify patients with HNPCC. For example, women with HNPCC may need to be screened for uterine cancer. Also, if the patient is known to have HNPCC, their relatives could also need genetic counseling. If HNPCC is absent then there is a greater risk of developing cancer and would require rigorous screening, accordingly. The second reason for performing MSI is to find if an early-stage colorectal cancer has instability in microsatellites as it may change the course of treatment. There are several ways to test for MSI. One way is to start using DNA test for MSI and another way is to first do an immunohistochemistry to see if certain proteins related to MSI are missing in the cancer cells followed by a DNA test.

Imaging tests: Imaging tests use sound waves, $\mathrm{x}$ rays, magnetic fields, or radioactive substances to create internal pictures of the body. Imaging tests may be done for several reasons like probing of a suspicious area or understanding the extent of metastasis or to monitor the effectiveness of treatment. Some of tests available are described briefly

(a) Flexible sigmoidoscopy: Sigmoidoscope is a flexible, lighted tube with a small video camera on the end and is used to visualize part of the colon and rectum. If the polyp is pre-cancerous (an adenoma) or if colorectal cancer is detected during the test, colonoscopy is required to detect polyps or cancer in the rest of the colon. The test is mostly uncomfortable due to the placing of air into the colon and significant bleeding as well as puncture of the colon are possible complications ${ }^{32,33}$.

(b) Colonoscopy: Colonoscopy is the main standard for the detection and screening of colorectal cancer ${ }^{34}$. A colonoscope is a longer version of a sigmoidoscope that can be used to scan the entire length of the colon and rectum. Special instruments can be passed through the colonoscope for biopsy or removal any polyps. As the possible side effect, the bowel preparation prior to the examination is unpleasant and the test itself may be uncomfortable, but the sedative usually eases most of the discomfort. Significant bleeding is slightly more likely occurrence with colonoscopy than with sigmoidoscopy.

(c) CT colonography (virtual colonoscopy): Computed tomography (CT or CAT) is an advanced scanning procedure that uses an $\mathrm{X}$ ray test to produce detailed 3-dimensional 
cross-sectional images of the body ${ }^{35}$. Unlike conventional x-ray, the CT scanner clicks several pictures from different angles. A computer then combines these pictures into images of slices to visualize the part of body being studied. CT scans take longer than normal $\mathrm{x}$-ray scans and require intravenous administration of a contrast dye or oral administration of a contrast fluid to help outline abnormality in high quality contrast. Although it is not invasive like colonoscopy, if polyps or other suspicious areas are detected on this test, a colonoscopy will still probably be needed to remove them or to explore them fully. Bloating or cramps might be observed and very rarely a risk of inflation or injury and puncture of colon, but this risk is thought to be much lesser compared to colonoscopy. Like other types of CT scans, this test involves minimal exposure to radiation.

(d) CT with portography: This test specifically targets the portal vein that leads into the liver from the intestine. In this test, contrast material is injected directly into the portal veins for generating contrast imaging of the liver ${ }^{36}$.

(e) CT-guided needle biopsy: If the cancer lies deep within the body, a CT scan can be used to guide a biopsy needle precisely into the suspected area ${ }^{26}$. In this procedure, a biopsy needle is pierced through the skin directly toward the suspected area. A fine-needle biopsy sample (tiny fragment of tissue) or a core needle biopsy sample (a thin cylinder of tissue) is then removed and observed under a microscope. This procedure is not used to biopsy a colon tumor, but is often carried out for tumors in the liver.

(f) Magnetic resonance imaging (MRI) scans: Like CT scans, MRI scans provide detailed images of soft tissues in the body ${ }^{37}$. But MRI scans use radio waves and strong magnets instead of x-rays. The energy from the radio waves is absorbed by the body and then released in a pattern depending on the type of body tissue and due to abnormalities in cells during certain diseases. A computer translates the pattern into a very detailed image of parts of the body. A contrast material called gadolinium is injected into a vein before the scan. MRI scans take longer time (up to 1 hour) than CT scans also cause discomfort due to claustrophobia (a fear of enclosed spaces). MRI scans are extremely helpful in patients with rectal cancers for visualizing spread of tumor to nearby organs. Endorectal MRI scans helps to increase the accuracy of regular MRI scans, wherein endorectal coil is inserted into the rectum for 30 to 45 minutes during the test.

Chest $\mathrm{x}$-ray: Chest x-ray is performed to detect the spread of colorectal cancer to the lungs.

Double-contrast barium enema: The double-contrast barium enema (DCBE) is also called an air-contrast barium enema ${ }^{38}$. It may also be referred to as a lower GI series. It is basically a type of $\mathrm{x}$-ray test that uses a chalky liquid of barium sulfate and air to outline the inner part of the colon and rectum to identify abnormal areas on x-rays. If suspicious areas are detected on this test, a colonoscopy is recommended. During the test, bloating of stomach and cramping are observed. Barium can cause constipation for a few days, and stools appear grey or white until the bowel is completely rid of the barium. Like with other x-ray tests, this test also involves radiation exposure.

Angiography: Angiography is an x-ray procedure for blood vessels. Contrast medium, or dye, is injected into an artery prior to $\mathrm{x}$-ray imaging ${ }^{39}$. Angiography is useful to distinguish anatomically the arteries that supply blood to tumors. A local anesthesia is often used to numb the area before inserting the catheter. However, angiography can be uncomfortable as the procedure involves insertion of a small catheter (a flexible hollow tube) into the artery leading to the liver for injecting the dye. Angiography may also be performed with the help of a CT scanner (CT angiography) or an MRI scanner (MR angiography). These techniques generate information about the blood vessels in the liver without the need for a catheter in the leg artery, although a contrast may still be needed.

Positron emission tomography (PET) scan: For a PET scan ${ }^{26}$, a form of radioactive sugar, known as fluorodeoxyglucose (FDG) is injected into the blood 
in very low dosages. Cancer cells in the body grow rapidly and absorb large amounts of the radioactive sugar. After about an hour the patients are placed inside the PET scanner that creates a picture of areas of radioactivity in the body using special cameras. A PET scan is used to accurately complement the results from other imaging and to analyze the spread of cancer to lymph nodes or other parts of the body. However, the images are not finely detailed like a CT or MRI scan.

\section{Ultrasound detection}

Ultrasound use sound waves and their echoes to generate a picture of internal organs or masses. A small microphone-like instrument called a transducer emits sound waves and gather the echoes that are reflected off from the body tissues. The echoes are converted by a computer into a black and white image that is displayed on a computer screen. This test is painless and does have radiation harms. The transducer is slid over the skin at the suspected areas under examination after lubrication with gel. Abdominal ultrasound can be used for detecting tumors in liver, gallbladder, pancreas, or elsewhere in the abdomen, but not in the colon. Two special types of ultrasound exams are sometimes used to evaluate colon and rectal cancers.

(a) Endorectal ultrasound: This test uses a special transducer that is inserted directly into the rectum ${ }^{40}$. It is used to create internal images all through the rectal wall and nearby organs or tissues such as lymph nodes.

(b) Intraoperative ultrasound: This examination is done during surgery once the abdominal cavity is surgically opened ${ }^{41}$. The transducer can be placed against the surface of the liver, making this test very useful for detecting the spread of colorectal cancer to the liver.

\section{Blood and stool tests to detect colorectal cancer}

These tests are carried out for the examination of the stools for signs of cancer. However, they are not as good at detecting polyps as the other tests described above, and any positive symptoms obtained from these methods would require a confirmation from a more invasive test such as colonoscopy.

Fecal occult blood test: The fecal occult blood test (FOBT) is used to find occult blood (blood invisible to the naked eye) in feces ${ }^{42}$. The FOBT detects blood in the stool through a chemical reaction. However, the test cannot distinguish if the blood is from the colon or from other parts of the digestive tract (such as the stomach). If this test is positive, a colonoscopy is recommended for determining the cause of bleeding. FOBT needs to be repeated every year and specimens from three consecutive bowel movements needs to be collected as smears on small squares of paper to be provided to the medical laboratory for testing within two weeks.

Fecal immunochemical test: The fecal immunochemical test (FIT) is also called an immunochemical fecal occult blood test (iFOBT) and is a much recently developed test to detect occult blood in the stools ${ }^{43}$. The FIT relies on chemical reaction with hemoglobin protein and is carried out essentially in the same way as the FOBT, but it does not require prior drug or dietary restrictions and sample collection may take less effort. This test is also less likely to react to bleeding from parts of the upper digestive tract, such as the stomach. Like FOBT, FIT also cannot detect a tumor that is not bleeding, so multiple stool samples are required to be tested and if the results are positive for hidden blood, a colonoscopy is recommended.

Stool DNA tests: Stool DNA tests rely on testing the stool for abnormal sections of DNA from cancer or polyp cells. DNA mutations associated with colorectal cancers are tested in this method. The pros and cons of individual tests are briefly stated in table 4.

Digital rectal examination: Digital rectal examination (DRE), is a lubricated-gloved finger examination. This is a simple and non-painful test and can detect masses in the anal canal or lower rectum. However, by itself, it is not a good test for detection of colorectal cancer due to its limited reach. Research has shown that this type of stool exam fails to detect more than $90 \%$ of colon abnormalities, including most cancers. 
Table 4: Pros and cons of colorectal cancer screening tests

\begin{tabular}{|c|c|c|}
\hline Name of the test & Pros & Cons \\
\hline $\begin{array}{l}\text { Flexible } \\
\text { sigmoidoscopy }\end{array}$ & $\begin{array}{l}\text { - Fairly quick and safe. } \\
\text { - Usually does not require full } \\
\text { - bowel preparation. } \\
\text { - Sedation is not used usually. } \\
\text { - Does not require a specialist. } \\
\text { - Procedure is repeated only } \\
\text { every } 5 \text { years. }\end{array}$ & $\begin{array}{l}\text { - Allows scanning of only about a third of the colon and } \\
\text { could miss out small polyps. } \\
\text { - Insufficient to remove all polyps. } \\
\text { - Could cause some discomfort to patient. } \\
\text { - A very small risk of bleeding, infection, or bowel tear } \\
\text { may exist. } \\
\text { - It is not full proof and a colonoscopy will be required if } \\
\text { an abnormality is detected. }\end{array}$ \\
\hline Colonoscopy & $\begin{array}{l}\text { - Usually it allows viewing of } \\
\text { the entire colon area. } \\
\text { - Can be used for biopsy and } \\
\text { removal of polyps. } \\
\text { - Repeated only every } 10 \\
\text { years. } \\
\text { - Can diagnose other diseases } \\
\text { as well. }\end{array}$ & $\begin{array}{l}\text { - Small polyps might remain undetected. } \\
\text { - Complete bowel preparation is needed. } \\
\text { - More expensive on a one-time basis than other forms of } \\
\text { testing. } \\
\text { - Sedation of some kind is usually required. } \\
\text { - May require certain post therapy rest and recovery time. } \\
\text { - Small risk of bleeding, bowel tears, or infection exists. }\end{array}$ \\
\hline $\begin{array}{l}\text { Double-contrast } \\
\text { barium enema } \\
\text { (DCBE) }\end{array}$ & $\begin{array}{l}\text { - Usually it allows viewing of } \\
\text { the entire colon area. } \\
\text { - It is relatively safe. } \\
\text { - Repeated only every } 5 \text { years. } \\
\text { - No sedation is required. }\end{array}$ & $\begin{array}{l}\text { - Small polyps might remain undetected. } \\
\text { - Complete bowel preparation is needed. } \\
\text { - Some false positive test may be detected in the results. } \\
\text { - Cannot remove polyps during testing. } \\
\text { - Colonoscopy will be needed if abnormality is detected. }\end{array}$ \\
\hline $\begin{array}{l}\text { CT colonography } \\
\text { (virtual } \\
\text { colonoscopy) }\end{array}$ & $\begin{array}{l}\text { - Fairly quick and safe } \\
\text { procedure. } \\
\text { - Usually it allows viewing of } \\
\text { the entire colon area. } \\
\text { - Repeated only every } 5 \text { years. } \\
\text { - No sedation is required. }\end{array}$ & $\begin{array}{l}\text { - Small polyps might remain undetected. } \\
\text { - Complete bowel preparation is needed. } \\
\text { - Some false positive test may be detected in the results. } \\
\text { - Cannot remove polyps during testing. } \\
\text { - Colonoscopy will be needed if abnormality is detected. } \\
\text { - It may be prone to health insurance related issues. }\end{array}$ \\
\hline $\begin{array}{l}\text { Fecal occult blood } \\
\text { test (FOBT) }\end{array}$ & $\begin{array}{l}\text { - No direct risk to the colon. } \\
\text { - No bowel preparation is } \\
\text { required. } \\
\text { - Sampling can be done at } \\
\text { home. } \\
\text { - Inexpensive. }\end{array}$ & $\begin{array}{l}\text { - May miss many polyps and some cancers. } \\
\text { - May tests also produce false-positive test results. } \\
\text { - May require having pre-test dietary limitations. } \\
\text { - Needs to be repeated every year } \\
\text { - Colonoscopy will be needed if abnormality is detected. }\end{array}$ \\
\hline $\begin{array}{l}\text { Fecal } \\
\text { immunochemical } \\
\text { test (FIT) }\end{array}$ & $\begin{array}{l}\text { - No direct risk to the colon. } \\
\text { - No bowel preparation is } \\
\text { required. } \\
\text { - Fairly inexpensive. }\end{array}$ & $\begin{array}{l}\text { - No pre-test dietary restrictions are required. } \\
\text { - Sampling can be done at home } \\
\text { - Needs to be repeated every year. } \\
\text { - Colonoscopy will be needed if abnormality is detected. } \\
\text { - May miss many polyps and some cancers. } \\
\text { - May produce false-positive test results. }\end{array}$ \\
\hline
\end{tabular}




\section{Survival rates for colorectal cancer by stage}

Survival rates are often a standard to define the process of prognosis. The ' 5 -year survival rate' refers to the percentage of patients who live at least 5 years after the cancer is diagnosed. However, in reality, many people outlive for much longer periods and many are completely cured as well. Other than the information of the type and the stage of cancer it also requires information like the grade of the cancer, the genetic changes in the cancer cells, the treatment received, and how well the cancer responds to treatment. Even after taking these factors into account, the survival rates are at best considered as rough estimates.

\section{Prevention of colon cancer}

Regular screening for colorectal cancer is one of the most powerful pre-requisites for preventing colorectal cancer. This is because most polyps can be identified and removed before they have the chance to turn into cancer. People who have no identified risk factors (other than age) optimally begin regular screening at age 50 years. Those having a family history or other risk factors for colorectal polyps or cancer, such as inflammatory bowel disease, should start screening at a younger age and/or receive much frequent screening.

Genetic testing: Numerous genetic screens are available to detect residing syndromes or other related colorectal cancers with respect to the clinical features and test of the mutated genetic representatives. FAP having a condition of adenomatous polyps in colon and rectum ranging from hundreds to thousands is resultant of mutations in by $A P C$, whereas those in $h M L H 1, h M S H 2$, hMSH6, hMSH3, hPMS2 lead to HNPCC in individuals having familial history of colorectal or other related hereditary cancers. Genetic eccentricity in $C D H 1$ and SMAD4, or PTEN and BMPR1A lead to hereditary gastric cancer or juvenile polyposis, respectively and associated with complications like gastric carcinoma and hamartomatous polyps in large bowel and stomach regions ${ }^{44}$.

Genetic testing ascertain familial members who have inherited a high risk for developing colorectal cancer due to syndromes such as FAP or HNPCC. Genetic counselors generate risk factors by taking into consideration certain characteristics associated with families having a past record of HNPCC, like (i) three or more relatives have colorectal cancer, (ii) at least one first-degree relative (parent, sibling, or child) (iii) at least two successive generations detected with colorectal cancer and (iv) at least one relative having cancer prior to the age of 50 years old. This thumb rule is also referred as the Amsterdam criteria ${ }^{45}$.

A second set of criteria, called the revised Bethesda guidelines, is used to determine whether a person with colorectal cancer should undergo genetic tests for HNPCC. These criteria include at least one of the following: (i) The person is younger than 50 years, (ii) the person has or had a second colorectal cancer or another cancer (endometrial, stomach, pancreas, small intestine, ovary, kidney, brain, ureters, or bile duct) that is associated with HNPCC, (iii) cancer has similar microscopic and diagnostic characteristics as HNPCC, (iv) the person has a firstdegree relative younger than 50 years who was diagnosed with colorectal cancer (v) the person has two or more first- or second-degree relatives diagnosed with colorectal cancer or an HNPCCrelated cancer at any age ${ }^{46}$.

The lifetime risk of colorectal cancer for people tested positive for HNPCC mutation may be as high as $80 \%$. In families known to carry an HNPCC gene mutation, doctors recommend an early colonoscopy (before 20 years of age). People who test positive for the gene change linked to FAP start colonoscopy during their teens.

\section{Management of risk for cancer}

The risk of developing colorectal cancer can be managed through controlling certain risk factors like diet and physical activity. Numerous studies have shown obesity and over-weight increase the risk of colorectal cancer in both men and women. Red meat intake, regular smoking and alcohol consumption are the major risk factors of colorectal cancer. In this regard, the following disease management steps have been recommended (i) increase in the intensity and amount of physical activity (ii) reduced intake of red and processed meats, (iii) consumption of recommended levels of calcium and vitamin D (iv) increased consumption of vegetables and fruits (v) avoiding weight gain around the midsection and (vi) avoiding excess consumption of alcohol. 
Vitamin D and calcium intake has the potency for lowering the colorectal cancer risk. However the possible risk of development of skin cancer and prostate cancer with exposure to sun and high calcium intake respectively, forced the scientific community not to recommend them. A few studies have also looked at a possible link between a diet high in magnesium and reduced colorectal cancer risk 2 .

\section{Management through drugs}

The regular use of aspirin and other nonsteroidal anti-inflammatory drugs (NSAIDs), such as ibuprofen (Motrin $\AA$, Advil $\AA$ ) and naproxen (Aleve $\left.{ }^{\circledR}\right)$ lowers the risk of colorectal cancer and adenomatous polyps ${ }^{47}$. From the studies it is evident that aspirin can prevent the growth of polyps in subjects who were previously treated for early stages of colorectal cancer or who previously had polyps removed. In due course, aspirin and other NSAIDs can cause serious or even life-threatening side effects such as bleeding from stomach irritation, which may outweigh the benefits of these medicines. For this reason, NSAIDs as a cancer prevention strategy is not recommended for people at average risk of developing colorectal cancer. On contrary, Celecoxib (Celebrex ${ }^{\circledR}$ ) has been approved by the US Food and Drug Administration for reducing polyp formation in people with familial adenomatous polyposis (FAP).

Hormonal therapy: Menopausal hormone therapy or combined hormone replacement therapy, involving external doses of estrogen and progesterone after menopause is known to reduce the risk of developing early stages of colorectal cancer in postmenopausal women ${ }^{48}$. Estrogen and progesterone also lowers the risk of developing osteoporosis (bone thinning) but can increase the risk of heart disease, blood clots, and cancers of the breast and lung. Menopausal hormone therapy requires thorough examinations of the risk factors of colorectal cancer patients. Certain studies have found the use of oral contraceptives (birth control pills) beneficial to lower the risk of colorectal cancer ${ }^{49}$.

\section{Eradication or removal of colorectal cancer}

The information discussed in this section represents the views of the doctors and nurses serving on the American Cancer Society's "Cancer Information
Database Editorial Board" and are based on their interpretation of studies published in medical journals, as well as respective professional experiences.

Treatment decisions: Once detected and staged, cancer treatment specialists usually advice for surgery, radiation therapy, chemotherapy or targeted therapy. Depending on the stage of the cancer, two or more treatment methods are combined simultaneously. The stage of the cancer is the important factor for the choice of treatment other than minor factors like the overall health, side effects of the treatment, and the probability of curing the disease, extending life, or relieving symptoms.

Surgery for colorectal cancer: The types of surgery used to treat colon and rectal cancers vary slightly.

Colon surgery: Surgery is often the main treatment for early stages of colon cancers.

Open colectomy: A colectomy (sometimes called a hemicolectomy, partial colectomy, or segmental resection) is conducted to remove a part of the colon, as well as nearby lymph nodes ${ }^{50,51}$. An incision is made in the abdomen and the part of the colon with the cancer along with a small segment of normal colon on either side of the cancer is cut and removed. The patients are prescribed with analgesics for 2 or 3 days and intravenous (IV) fluids are provided for the first couple of days after the surgery.

Laparoscopic assisted colectomy: This is a newer approach to remove a part of the colon and nearby lymph nodes for early stage cancers ${ }^{50,51}$. Instead of making one long incision in the abdomen, the surgeon makes several smaller incisions. Special long instruments are inserted through these incisions to remove parts of the colon and lymph nodes. The instrument "laparoscope", has a small attached video camera on the end to visualize the inside of the abdomen. As the incisions are smaller than with an open colectomy, patients recover slightly faster and encounter lesser pain. Laparoscopic-assisted surgery is as likely to be curative like the open approach for colon cancers. However, the surgery requires special expertise. 
Polypectomy and local excision: This surgical procedure is also carried out for early colon cancers polyps that cannot be removed by colonoscopic surgery ${ }^{50}$. When this is done, the surgeon does not have to cut into the abdomen. During a polypectomy, the cancer is removed by cutting the atits stalk (the area that resembles the stem of a mushroom).

\section{Rectal surgery}

Surgery is usually the main method of treatment for rectal cancer ${ }^{37}$, although radiation and chemotherapy is often being provided before or after surgery. Several surgical methods can be used for removing or destroying rectal cancers.

Polypectomy and local excision: This is done with instruments inserted through the anal opening, without making a surgical opening in the abdomen.

\section{Local trans-anal resection (full thickness resection):}

This operation cuts through all layers of the rectum as well as some surrounding normal rectal tissue for removing the cancer and then closes the hole in the rectal wall. This procedure can be used to remove some T1, N0, M0 and stage I rectal cancers that are relatively small and not too far from the anus. It is usually done with local anesthesia in conscious state of the patient ${ }^{50}$.

Trans-anal endoscopic microsurgery (TEM): This operation can be used for early T1, N0, M0 and stage I cancers ${ }^{50}$. A specially designed magnifying scope is inserted through the anal opening and into the rectum, allowing the surgeon to do a trans-anal resection with high precision and accuracy.

Low anterior resection: Stage I rectal cancers and most of the stage II and stage III cancers in the upper third of the rectum can be removed by low anterior resection (Nelson et al 2001) ${ }^{50}$. In this operation, the part of the rectum containing the tumor is removed without affecting the anus. The colon is then attached to the remaining part of the rectum so that after the surgery bowel movement is normal. If radiation and chemotherapy have been provided prior to the surgery, it is common for a temporary ileostomy to be made wherein the end portion of the small intestine (the ileum) is brought out through a hole in the abdominal wall. Usually this procedure is reversible and the intestines are reconnected about 8 weeks later.

Proctectomy with colo-anal anastomosis: Some stage I and most stage II and III rectal cancers occurring in the middle and lower third of the rectum requires removal of the entire rectum (proctectomy) ${ }^{50}$. During colo-anal anastomosis, a small pouch is created by doubling back a short segment of colon (colonic J-pouch) or by enlarging a segment (coloplasty). This small reservoir of colon then functions as a storage space for fecal matter mimicking the functions of rectum prior to the surgery. While special techniques are needed to avoid a permanent colostomy, there is a need to have a temporary ileostomy opening for about 8 weeks while the bowel heals. A second operation is then carried out to reconnect the intestines and close the ileostomy opening.

Abdominoperineal resection (APR): This operation is more common than the low anterior resection ${ }^{50}$. It can be used to treat some of the stage I cancers and many stage II or stage III rectal cancers in the lower third portion of the rectum, especially if the cancer is growing into the sphincter muscle (the muscle that closes the anal aperture preventing stool leakage). During APR, one incision is made in the abdomen, and another in the perineal area around the anus. This incision allows the removal of the anus and the tissues surrounding it, including the sphincter muscle. As the anal aperture is removed, a permanent colostomy is needed to allow stool to find a path out of the body.

Pelvic exoneration: If the rectal cancer is growing into nearby organs, a pelvic exoneration is recommended ${ }^{50}$. Not only the rectum is removed, but also nearby organs such as the bladder, prostate (in men), or uterus (in women) depending on the spread of cancer. A colostomy is required after pelvic exoneration.

\section{Side effects of colorectal surgery}

Potential side effects of surgery depend on several factors, including the extent of the operation and patient's general health before surgery. Most patients sense at least some pain after the operation, but usually it can be controlled with medicines if needed 
${ }^{52}$. Other problems may include bleeding, blood clots, and damage to nearby organs. Rarely, the new connections between the ends of the intestine may detach and leak leading to infection. After the surgery, a scar tissue can develop in the abdomen causing organs or tissues to stick together. These are called adhesions. In certain cases, adhesions can also block the bowel and would require further surgery. Some patients may need a temporary or permanent colostomy (or ileostomy) after surgery ${ }^{52}$. This may take some time to get used to and may require some lifestyle adjustments.

In males, an APR is known to prevent penis erections and ability to reach orgasm ${ }^{53}$. An APR can also damage the nerves that control ejaculation leading to "dry" orgasms (orgasms without semen). Sometimes the surgery causes retrograde ejaculation, causing the semen to transcend backward into the bladder during an orgasm. These situations can greatly affect fertility. In females, abdominal adhesions (scar tissue) may sometimes lead to pain or discomfort during intercourse. If cases where the uterus is removed, pregnancy is not a possibility.

\section{Other treatments for colorectal cancer metastases}

Surgery for metastasized cancer that has spread to other organs can help increase life expectancy. If it's not possible to remove the tumors with surgery, nonsurgical treatments are adopted to destroy (ablate) tumors, however, these methods are less likely to be curative $^{54,55}$.

Radiofrequency ablation: Radiofrequency ablation (RFA) uses high-energy radio waves to kill tumors. A thin, needle-like probe is placed through the skin and into the tumor under CT or ultrasound guidance. An electric current is then run through the tip of the probe, generating high-frequency radio waves that heat the tumor and destroy the cancer cells.

Ethanol (alcohol) ablation: This method is also known as percutaneous ethanol injection (PEI) and requires injection of concentrated alcohol directly into the tumor to kill the cancer cells.

Cryosurgery (cryotherapy): Cryosurgery destroys a tumor by freezing it with a metal probe ${ }^{56}$. The probe is guided through the skin and into the tumor using ultrasound. Very cold gas is passed through the probe to freeze the tumor, thus killing the cancer cells. This method can treat larger tumors compared to other ablation techniques.

Hepatic artery embolization: This technique is performed by reducing the blood flow in the hepatic artery that feed most of the cancer cells ${ }^{57}$. A catheter is injected into an artery in the inner thigh and it threads it up into the liver. A dye is usually injected into the bloodstream during this time to allow the monitoring of the path of the catheter by angiography. Once the catheter is in place, small particles are injected into the artery to plug it up. Embolization also reduces some of the blood supply to the normal liver tissues and can be dangerous for patients with diseases such as hepatitis and cirrhosis.

Radiation therapy for colorectal cancer: Radiation therapy uses high-energy rays (such as X-rays) or particles to destroy cancer cells. It may be used as a part of treatment for either colon or rectal cancer ${ }^{58}$. Combination with chemotherapy can make radiation therapy more effective against some colon and rectal cancers. Radiation therapy is mainly used in patients with colon cancer when the cancer has attached to an internal organ or the lining of the abdomen. It is also used to treat colon cancer that has spread to the bones or brain. For rectal cancer, radiation therapy can be carried out either before or after surgery to help prevent the cancer from reappearing in the location of origin. Providing radiation prior to surgery lowers the risk of resurfacing of the tumor in the pelvis. It may also result in fewer complications like scar formation that cause problems with bowel movements.

Different types of radiation therapy can be used to treat colon and rectal cancers is described below

(a) External-beam radiation therapy: In this, radiation is focused on the cancer from a machine called a linear accelerator from outside of the body. The correct path, angle and dosage of radiation are carefully measured before the start of treatment. External-beam radiation therapy is similar to obtaining an x-ray, however, the radiation is more intense. The procedure is painless and lasts only a few minutes, but the pretreatment procedures usually takes longer. 
(b) Endocavitary radiation therapy: This type of treatment is used for some rectal cancers $^{59}$. A small device is inserted through the anus and into the rectum to deliver highintensity radiation over a few minutes. The cycle is repeated about 3 times at about 2week intervals for a complete dose. The advantage of this approach is that the radiation reaches the rectum without passing through the skin and other tissues of the abdomen, making it less likely to be prone to side effects.

(c) Brachytherapy (internal radiation therapy): Brachytherapy makes use of small pellets of radioactive material that are placed next to or directly into the cancer. The radiation travels only a short distance, limiting the effects on surrounding healthy tissues. This is generally a one-time only procedure and doesn't require repeated cycles of therapy.

\section{Chemotherapy for colorectal cancer}

Chemotherapy (or simply, chemo) is defined as a treatment using anti-cancer drugs ${ }^{60}$. Chemotherapy exploits natural or synthetic chemicals for lowering the risk of developing cancer and is implemented as a systemic or a regional therapy. In systemic approach the drugs are administered orally or intravenously allowing them to enter the bloodstream and reach all parts of the body. In regional chemotherapy, the drugs are directed to the arteries connecting to the specific tumor affected locations and thus, reducing the dosage of the drug as well as systemic spread to other body parts. Drugs can also be used to help shrink tumors and relieve symptoms for cancers that have spread to other organs, such as the liver. Although it is not likely to cure the cancer, it improves longevity. The commonly used chemotherapeutic drugs include a vitamin-like drug leucovorin sold under the brand name 5-Fluorouracil (5-FU), a pill form drug Capecitabine (Xeloda), which converts to 5-FU at the site of action. Additionally, a combination of drugs in pill form such as Irinotecan (Camptosar), tipiracil (Lonsurf) and Oxaliplatin (Eloxatin) Trifluridine is prescribed to be more effective for treating the tumor 61.
Chemo drugs are preferably administered as neoadjuvant or adjuvant in cases of advanced cancers. Hepatic artery infusion, where chemo is given directly into the hepatic artery, is an example of regional chemotherapy that is sometimes used for colon cancer that has spread to the liver. For shrinking the rectal cancer and to ease the surgery, neoadjuvant chemo drug is administered along with radiation therapy. An adjuvant chemo drug is administered after surgery to kill the cancer cells that have escaped imaging tests or spread to other parts of body, thus preventing the cancer from reappearing. Usually it is practiced after all the visible cancer has been removed to a level of lower probability of resurfacing. Mechanistically, it kills the small number of cancer cells that may have been undetected and left behind after surgery.

General side effects observed during chemotherapy depend on the drug dosage and time of consumption. It may manifest as loss of appetite, nausea, vomiting, diarrhea lower white blood count and fatigue to hair loss and profuse bleeding. In parallel, the specificity of drugs like 5-FU infusion can initiate redness and systemically spread as pain and sensitivity in palms and soles. Oxalplatin can induce nerve damage accompanied by allergic reactions. Diarrhea is known to be a common side effect of irinotecan. Although most of these side effects tend to diminish after the completion of treatment, but some tend to retain for a longer time such as numbness and tingling sensation caused by Oxalplatin ${ }^{61}$.

Chemo drugs are very strong medicines that can also affect some healthy cells in the body. Hence, the drugs are administered in cycles with every period of treatment followed by a rest period to allow recovery of the body. The drugs most often used for colorectal cancer include:

(i) 5-Fluorouracil (5-FU) is often administered along with the vitamin-like drug leucovorin (also called folinic acid) to improve its efficiency. A similar drug called levo-leucovorin may also be used instead.

(ii) Capecitabine (Xeloda $\left.{ }^{\circledR}\right)$ is available in form of pills. Once inside the body, it is converted to 5-FU after entering the tumor site.

(iii) Irinotecan (Camptosar $\left.{ }^{\circledR}\right)$

(iv) Oxaliplatin (Eloxatin $\left.{ }^{\circledR}\right)$ 
"FOLFOX" a combination of 5-FU, leucovorin, and oxaliplatin as well as "CapeOx" a combination of Capecitabine and oxaliplatin are considered stronger medications but also have higher side effects. Sometimes, the chemo drugs are combined with a targeted therapy. For rectal cancer, chemo drug with 5-FU or capecitabine combined with radiation may be suggested before surgery (neoadjuvant treatment).

\section{Targeted therapy}

Several targeted therapies are already used to treat colorectal cancer, including bevacizumab (Avastin), cetuximab (Erbitux), and panitumumab (Vectibix) ${ }^{62}$. Targeted therapies are currently used to treat advanced cancers, but newer studies are trying to determine if using them in conjunction with chemotherapy in earlier stage cancers or as a part of adjuvant therapy may further reduce the risk of recurrence.

EGFR targeted drugs: Cetuximab (Erbitux $\left.{ }^{\circledR}\right)$ and panitumumab (Vectibix $\AA$ ) are both monoclonal antibodies that specifically attack the epidermal growth factor receptor (EGFR) ${ }^{62}$, a molecule that is often produced in high amounts on the surface of cancer cells and aids in their growth. Cetuximab is used in metastatic colorectal cancer, either as part of first-line treatment or after other treatments. Panitumumab is used to treat metastatic colorectal cancer, usually after other treatments have been tried. About 4 out of 10 colorectal cancers have mutations (defects) in the KRAS gene, which make these drugs ineffective. It is common practice to test the tumor for this genetic mutation and the use of these drugs is avoided in patients who carry the mutation. Mutation in the $B R A F$ gene may make the drugs ineffective. Both the drugs are administered by IV infusion, either once a week or every alternate week. The most common side effects include skin problems such as an acne-like rash on the face and chest during treatment, which in some cases can also lead to infections. The skin problems with panitumumab can be more serious and lead to skin peeling. Other side effects include headache, tiredness, fever, and diarrhea. A rare but serious side effect of these drugs is an allergic reaction during the infusion, which could cause problems with breathing and low blood pressure and is avoided by administration of additional medication.

Other targeted drugs: Regorafenib (Stivarga $\AA$ ) is another targeted drug used for advanced colorectal cancer. It is a type of targeted therapy classified as a kinase inhibitor ${ }^{62}$. Kinases are proteins on or near the surface of a cell that transmit important signals to the cell's control center. Regorafenib blocks several kinase proteins that either prompt tumor cells to grow or help in angiogenesis to form new blood vessels supplying nutrients to the tumor. Blocking these proteins can help stop the growth of cancer cells. This drug is administered in pill form and common side effects include fatigue, decreased appetite, handfoot syndrome (redness and irritation of the hands and feet), diarrhea, sores in the mouth and throat, weight loss, voice change, infections, and high blood pressure. Some serious side effects that can occur include liver damage, severe bleeding, and perforations in the stomach or intestines.

\section{Immunotherapy}

Researchers are searching for vaccines to try to treat colorectal cancer or prevent it from reappearing post-treatment. Vaccines are designed to boost the patient's immune reaction to fight colorectal cancer more effectively. Studies are being carried out to remove the patient's own immune system cells (specifically the dendritic cells) from the blood, manipulating them in laboratory to make them more aggressive in attacking cancer cells, and then reintroducing them back into the patient's body. Currently, these types of vaccines are only available in clinical trials ${ }^{63}$.

\section{Complementary and alternative therapies for colorectal cancer}

Complementary and alternative therapies are adapted to treat cancer or relieve symptoms not mentioned in the medical statements ${ }^{64}$. These methods can include use of vitamins, herbs, and special diets, or other methods such as acupuncture or massage. Complementary therapy are methods that are used along with regular medical care. Alternative therapies are used in place of regular medical treatment. 
(i) Complementary methods: Complementary therapy is not offered as cure of cancer, but are used to relieve disease symptoms. Some methods that are used along with regular treatment are meditation to reduce stress, acupuncture to help relieve pain or peppermint tea to relieve nausea. These methods are not scientifically documented.

(ii)

Alternative treatments: Alternative therapy have possibilities to offer as cancer cures. These treatments have not been proven safe and effective in clinical trials. Some of these methods may even pose danger, or have lifethreatening side effects. Delays or interruptions in medical treatments may give the more time for the cancer to outgrow to stages less likely of cure.

\section{CONCLUSION:}

Colorectal cancer is mainly caused due to increasing age and lifestyle disorders as well as rarely caused by heritable or acquired genetic changes. Colorectal cancers are screened in accordance to risk factors and active surgery plays an important part in treatment of the cancer. Technological improvements have led to wide array of diagnostic, detection, imaging, surgical and therapeutics methods of the disease. However, general awareness of the disease including genetic counseling remains a potent protocol for preventive measures of early detection and treatment of diseases. The review compiles different guidelines for screening, treatment and

\section{REFERENCES:}

1. Cancer facts and figures, 2014, American Cancer Society.https://www.cancer.org/rese arch/cancer-facts-statistics/all-cancer-factsfigures/ cancer-facts-figures-2014.html

2. Edge SB. AJCC Cancer staging manual, $7^{\text {th }}$ ed. Springer, Chicago, Illinois; 1998.

3. Tumwine LK, Kagimu M, Ocama P, Segamwenge I, Masiira-Mukasa N, Wamala $\mathrm{D}$, et al. Atypical representation of colon adenocarcinoma: A case report. J Med Case Rep. 2012; 6:58.

4. Lin H-H, Lin J-K, Jiang J-K, Lin C-C, Lan Y-T, Yang S-H, et al. Clinicopathological therapeutics available for this widely prevalent disease.

\section{ACKNOWLEDGEMENT:}

The authors are thankful to Skanda Life Sciences Pvt. Ltd, Bengaluru, for their constant suggestions during the study

\section{CONFLIT OF INTEREST:}

We declare that we have no conflict of interest.

\section{ABBREVIATIONS:}

GIST Gastrointestinal Stromal Tumors; IBD Inflammatory Bowel Disease; IBS Irritable Bowel Syndrome; FAP Familial Adenomatous Polyposis; HNPCC Hereditary Non-Polyposis Colorectal Cancer; 5-FU 5-FluoroUracil; NSAIDs NonSteroidal Anti-Inflammatory Drugs; DRE Digital Rectal Examination; CT or CAT Computed Tomography; FOBT/ iFOBT Fecal Occult Blood Test/ Immunochemical Fecal Occult Blood Test; FIT Fecal Immunochemical Test; CBC Complete Blood Count; CEA Carcino embryonic antigen; MSI Microsatellite Instability; MRI Magnetic Resonance Imaging; PET Positron Emission Tomography; FDG Fluorodeoxyglucose; IV Intravenous; TEM TransAnal Endoscopic Microsurgery; TME Total Mesorectal Excision; APR Abdominoperineal Resection; RFA Radiofrequency Ablation; PEI Percutaneous Ethanol Injection; EGFR Epidermal Growth Factor Receptor

analysis of colorectal carcinoid tumors and patient outcomes. World J Surg Oncol. 2014; 12:366.

5. Zanwar S, Ostwal V, Sahu A, Jain D, Ramaswamy A, Saklani A, et al. Rectal GIST-Outcomes and viewpoint from a tertiary cancer center. Indian $\mathrm{J}$ Gastroenterol. 2016; 35:445.

6. Rigter LS, Spaander MCW, Moons LM, Bisseling TM, Aleman BMP, de Boer JP, et al. Colorectal cancer surveillance in Hodgkin lymphoma survivors at increased risk of therapy-related colorectal cancer: study design. BMC Cancer. 2007; 17:112. 
7. Thiels CA, Bergquist JR, Krajewski AC, Lee HE, Nelson H, Mahis KL, Habermann $\mathrm{EB}$, et al. Outcomes of primary colorectal sarcoma: A national cancer data base (NCDB) review. J Gastrointest Surg. 2017; 21:560.

8. Haggar FA, Boushey RP. Colorectal cancer epidemiology: Incidence, mortality, survival and risk factors. In: Boushey RP, editors. Clinics in Colon and Rectal Surgery. New York: Thieme Medical Publishers Inc; 2009. p. 191-197.

9. Janout V, Kollárová H. Epidemiology of colorectal cancer. Biomed Pap Med Fac Univ Palacku Olomouc Czech Repub. 2001; 145:5.

10. Skibber J, Minsky B, Hoff P. Cancer of colon and rectum. In: DeVita VT Jr, Hellmann S, Rosenberg SA, editors. Cancer: Principles and Practice of Oncology. Philadelphia: William and Wilkins; 2001. p. 1216-1271.

11. Jackson-Thompson J, Ahmed F, German RR, Lai SM, Friedman C. Descriptive epidemiology of colorectal cancer in the United States, 1998-2001. Cancer. 2006; 107:1103.

12. Wilmink ABM. Overview of the epidemiology of colorectal cancer. Dis Colon Rectum. 1997; 40:483.

13. Steinke V, Engel C, Büttner R, Schackert HK, Schmiegel WH, Propping P. Hereditary nonpolyposis colorectal cancer (HNPCC)/Lynch syndrome. Dtsch Arztebl Int. 2013; 110:32.

14. Hamilton SR, Liu B, Parsons RE, Papadopoulos N, Jen J, Powell SM, et al. The molecular basis of Turcot's syndrome. N Engl J Med. 1995; 332:839.

15. Kopacova M, Tacheci I, Rejchrt S, Bures J. Peutz-Jeghers syndrome: diagnosic and therapeutic approach. World J Gastroenterol. 2009; 15:5397.

16. Venesio T, Balsamo A, D'Agostino VG, Ranzani GN. MUTYH-associated polyposis (MAP), the syndrome implicating base excision repair in inherited predisposition to colorectal tumors. Front Oncol. 2012; 2:1.
17. Gryfe R, di Nicola N, Gallinger S, Redston $\mathrm{M}$. Inherited colorectal polyposis and cancer risk of the APC I1307K polymorphism. Am J Hum Genet. 1999; 64:378.

18. Larsson SC, Orsini N, Wolk A. Diabetes Mellitus and risk of colorectal cancer: a meta-analysis. J Natl Cancer Inst. 2005; 97:1679.

19. Anderson AS, Caswell S, Macleod M, Craigie AM, Stead M, Steele RJC, et al. Awareness of lifestyle and colorectal cancer risk: findings from the BeWEL study. BMC Res Int. 2015; 2015:ID 871613.

20. Schernhammer ES, Laden F, Speizer FE, Willett WC, Hunter DJ, Kawachi I, et al. Night-shift work and risk of colorectal cancer in the nurses' health study. J Natl Cancer Inst. 2003; 95: 825.

21. Travis LB, Curtis RE, Fraumeni Jr JF, Boice Jr JD, Storm H, Andersson M, et al. Risk of second malignant neoplasms among longterm survivors of testicular cancer. J Natl Cancer Inst. 1997; 89:1429.

22. Brenner DJ, Curtis RE, Hall EJ, Ron E. Second malignancies in prostrate carcinoma patients after radiotherapy compared with surgery. Cancer. 2000; 88:398.

23. Plawski A, Banasiewicz T, Borun $\mathrm{P}$, Kubaszewski L, Krokowicz P, SkrzypczakZielinska $\mathrm{M}$, et al. Familial adenomatous polyposis of the colon. Hered Cancer Clin Pract. 2013; 11:15.

24. Shima K, Morikawa T, Yamauchi M, Kuchiba A, Imamura $\mathrm{Y}$, Liao $\mathrm{X}$, et al. $T G F B R 2$ and BAX mononucleotide tract mutations, microsatellite instability, and prognosis in 1072 colorectal cancers. PLoS One. 2011; 6:e25062.

25. Al-Shamsi HO, Jones J, Fahmawi Y, Dahbour I, Tabash A, Abdel-Wahab R, et al. Molecular spectrum of $K R A S, N R A S, B R A F$, PIK3CA, TP53, and APC somatic gene mutations in Arab patients with colorectal cancer: determination of frequency and distribution pattern. J Gastrointest Oncol. 2016; 7:882.

26. Saunders TH, Ribeiro HKM, Gleeson FV. New techniques for imaging colorectal cancer: The use of MRI, PET and 
radioimmunoscintigraphy for primary staging and follow-up. Br Med Bull. 2002; 64:81.

27. Payne JR. International colorectal carcinoma staging grading. Dis Colon Rectum. 1989; $32: 282$.

28. Forones NM, Tanaka M. CEA and CA 19-9 as prognostic indexes in colorectal cancer. Hepatogastroenterol. 1999; 46:905.

29. Arrieta O, Villarreal-Garza C, MartínezBarrera L, Morales M, Dorantes-Gallareta, Peña-Curiel $\mathrm{O}$, et al. Usefulness of serum carcinoembryonic antigen (CEA) in evaluating response to chemotherapy in patients with advanced non small-cell lung cancer: A prospective cohort study. BMC Cancer. 2013; 13:254.

30. Tan C, Du X. KRAS mutation testing in metastatic colorectal cancer. World J Gastroenterol. 2012; 18:5171.

31. Dinjens WNM, van Leerdam ME, Wagner A. On the advent of MSI testing of all colorectal cancers and a substantial part of other Lynch syndrome-related neoplasms. Expert Rev Mol Diagn. 2010; 10:381.

32. Burt RW, Barthel JS, Dunn KB, David DS, Drelichman E, Ford JM, et al. NCCN Clinical practice guidelines in oncology. Colorectal cancer screening. J Natl Compr Cancer Netw. 2010; 8:8.

33. Moshkowitz M, Arber N. Emerging technologies in colon cancer screening. Surg Oncol Clin N Am. 2005; 14:723.

34. Lieberman DA, Weiss DG, Bond JH, Ahnen DJ, Garewal H, Harford WV, et al. Use of colonoscopy to screen asymptomatic adults for colorectal cancer. J Med. 2000; 343:162.

35. Heiken JP. CT colonography ('virtual colonoscopy'): Is it ready for colorectal cnacer screening? Cancer Imaging. 2015; $3: 146$.

36. Soyer P. CT during arterial portography. Eur Radiol. 1996; 6:349.

37. Torkzad MR, Påhlman L, Glimelius B. Magnetic resonance imaging (MRI) in rectal cancer: A comprehensive review. Insights Imaging. 2010; 1:245.

38. Rex DK, Rahmani EY, Haseman JH, Lemmel GT, Kaster S, Buckley JS. Relative sensitivity of colonoscopy and barium enema for detection of colorectal cancer in clinical practice. Gastroenterology. 1997; 112:17.

39. Gu J, Ma ZL, Li Y, Li M, Xu GW. Angiography for diagnosis and treatment of colorectal cancer. World J Gastroenterol. 2003; 9:288.

40. Edelman BR, Weiser MR. Endorectal ultrasound: Its role in the diagnosis and treatment of rectal cancer. Clin Colon Rectal Surg. 2008; 21:167.

41. Ellebæk SB, Fristrup CW, Mortensen MB. Intraoperative ultrasound as a screening modality for the detection of liver metastases during resection of primary colorectal cancer-A systematic review. Ultrasound Int Open. 2017; 3-E60.

42. Stracci F, Zorzi M, Grazzini G. Colorectal cancer screening: Tests, strategies, and perspectives. Public Health. 2014; 2:1.

43. Levin B, Brooks D, Smith RA, Stone A. Emerging technologies in screening for colorectal cancer: CT colonography, immunochemical fecal occult blood tests, and stool screening using molecular markers. CA Cancer J Clin. 2003; 53:44.

44. Kaz AM, Brentnall TA. Genetic testing for colon cancer. Nat Clin Pract Oncol. 2006; 3:670.

45. Winawer S, Fletcher R, Rex D, Bond J, Burt $\mathrm{R}$, Ferrucci $\mathrm{J}$, et al. Colorectal cancer screening and surveillance: clinical guidelines and rationale-update based on new evidence. Gastroenterology. 2003; 124:544.

46. Umar A, Boland CR, Terdiman JP, Syngal $\mathrm{S}$, de la Chapelle A, Rüschoff J, et al. Revised Bethesda guidelines for hereditary nonpolyposis colorectal cancer (Lynch syndrome) and microsatellite instability. J Natl Cancer Inst. 2010; 96:261.

47. Ruder EH, Laiyemo AO, Graubard BI, Hollenbeck AR, Schatzkin A, Cross AJ. Non-steroidal anti-inflammatory drugs and colorectal cancer risk in large, prospective cohort. Am J Gastroenterol. 2011; 106:1340.

48. Rennert G, Rennert HS, Pinchev M, Lavie O, Gruber SB. Use of hormone replacement 
therapy and the risk of colorectal cancer. $\mathrm{J}$ Clin Oncol. 2009; 27:4542.

49. Fernandez E, la Vecchia C, Franceschi S, Braga C, Talamini R, Negri E, et al. Oral contraceptive use and risk of colorectal cancer. Epidemiology. 1998; 9:295.

50. Nelson H, Petrelli N, Carlin A, Couture J, Fleshman J, Guillem J, et al. Guidelines 2000 for colon and rectal cancer surgery. J Natl Cancer Inst. 2001; 94:583.

51. Chokshi RJ, Abdel-Misih S, Bloomston M. Surgical management of colorectal cancer: A review of the literature. Indian $\mathrm{J}$ Surg. 2009; 71:350.

52. Kirchoff P, Clavien P-A, Hahnloser D. Complications in colorectal surgery: Risk factors and preventive strategies. Patient Saf Surg. 2010; 4:5.

53. Schover LR, van der Kaaij M, van Dorst E, Creutzberg C, Huyghe E, Kiserud CE. Sexual dysfunction and infertility as late effects of cancer treatment. EJC Suppl. 2014; $12: 41$.

54. Nosher JL, Ahmed I, Patel AN, Gendel C, Murillo PG, Moss R, et al. Non-operative therapies for colorectal liver metastases. J Gastrointest Oncol. 2014; 6:224.

55. Oxenberg RP, Hochwald SN, Nurkin S. Ablative therapies for colorectal polyps and malignancy. BMC Res Intl. 2014; 2014:ID986352.

56. Bilchik AJ, Wood TF, Allegra D. Cryosurgical ablation and radiofrequency ablation for unresectable hepatic malignant neoplasms. A proposed Algorithm. Arch Surg. 2000; 135:657.

57. Wang DS, Louie JD, Sze DY. Intra-arterial therapies for metastatic colorectal cancer. Semin Intervent Radiol, 2013; 30:12.

58. Kye B-H, Cho H-M. Overview of radiation therapy for treating colorectal cancer. Ann Coloproctol. 2014; 30:165.

59. Lavertu S, Schild SE, Gunderson LL, Haddock MG, Martenson JA. Endocavitary radiation therapy for rectal adenocarcinoma: 10-year result. Am J Clin Oncol 2003; 26:508.

60. Moertel CG. Chemotherapy for colorectal cancer. N Engl J Med. 1994; 330:1136.

61. Nicum S, Midgley R, Kerr DJ. Chemotherapy for colorectal cancer. J R Soc Med. 2000; 93:416.

62. Moriarity A, O'Sullivan J, Kennedy J, Mehigan B, McCormick P. Current targeted therapies in the treatment of advanced colorectal cancer: A review. Ther Adv Med Oncology. 2016; 8:1.

63. Burgdorf SK. Dendritic cell vaccination of patients with metastatic colorectal cancer. Dan Med Bull. 2010; 57:B4171.

64. Ezeome ER, Anarado AN. Use of complementary and alternative medicine by cancer patients at the University of Nigeria teaching hospital, Enugu, Nigeria. BMC Complement Altern Med. 2007; 7:28. 